International Journal of Engineering \& Technology, $7(2.33)(2018) 239-244$
International Journal of Engineering \& Technology
WPC
Website: www.sciencepubco.com/index.php/IJET
Research paper

\title{
Design and experimental analysis of morphing wing based on biomimicry
}

\author{
Mugeshwaran A ${ }^{1}$ *, Guru Prasad Bacha ${ }^{1}$, Rajkumar $\mathbf{S}^{1}$ \\ ${ }^{1}$ Faculty of Engineering and Technology, Department of Aerospace Engineering, SRM Institute of Science and Technology, Chennai \\ *Corresponding author E-mail: amugeshwaran125@gmail.com
}

\begin{abstract}
In this paper narrate about the study of aerodynamics in the multi-section morphing wing variation of baseline configuration to camber con-figuration. In particularly NACA 0012, section tried to morph as NACA 9312 camber section to achieve the lift to drag ratio in the flight condition based on the bio-mimicry. The CAD model and fabricated morphing wing in geometry scale of $20 \mathrm{~cm}$ chord and a $36 \mathrm{~cm}$ wing-span, with aluminum material ribs divided into 6 sections. Each section was able to rotate approximately 6 degrees without causing a discontinuity in the wing surface and also in order avoid the control surface based on the bio mimicry the morphing wing was designed and tested. DC-motor located at main spar with the two equal gear ratio the rib section used to morph the wing through the linear mechanical linkages. The aluminum ribs section are made through the EDM-Wire cut machining process for capable to actuate the morphing wing. In each section morphing wing can able provide up to 10 percent variation in the symmetrical airfoil to the cambered airfoil. The experimental test of the morphing was carried out in the cascade tunnel by force balancing method and the lift and drag output are compared.
\end{abstract}

Keywords: Morphing Wing; Dc-Actuator; Wing Skin; Ribs; Spars.

\section{Introduction}

Reduction in Fuel consumption in an aircraft is a major area that has vast potential to explore. A great deal of research has been focused on achieving this goal. The use of morphing wing in the past have shown us the efficient ways of fuel consumption. Our method trying to reduce drag by morphing the wing to satisfy different flight conditions is another way to satisfy different flight conditions so fuel can be consumed efficiently which is discussed by the Martins et al. Various concepts in the past have illustrated different ways in which wing can be morphed. Our method of reducing drag and enhancing lift during flight promises us by providing better performance of the wing based on the design and materials discussed by Martins et al. Our main focus was to achieve an actuation system that is convenient in the use to change the wing surfaces. The initial inspiration from the biomimicry Tunçöz et al developed the wing concept began with the desire to change the wing by deflecting only the trailing edge portion of the wing without having any gap between each portion in the different angle with help of the internal mechanism. Nadar et al investigated aerodynamic in the fabricated model of the three-rib section and we made as a concept model, but the wing did not provide smooth change during cambered configuration, therefore the idea of creating more sections out of the wing rib to provide the discrete but smooth change in camber was introduced. The wing rib was divided into six sections from the leading edge to the trailing edge section. Separating the wing into section provided change in the shape of the airfoil each section can able to rotate easily which related to the neighboring sections. The actuation system considers for this case but due to the difficulty in connecting the section which not capable of the control system, this actuation idea was not applied. The use of simple linkages system with linear continuous link seemed to work well with the DC Motor Actuation. A detailed description of the morphing wing design is discussed in the next sections.

\subsection{Outline}

This research focuses on designing and testing a morphing wing model using multi-section ribs and DC motor-actuator. The model consists of four sets of NACA0012 airfoil rib-sections which is dived into six section connected through sub-spars, with the main spar located at one-sixth of the chord of the airfoil. Due to a limitation in space of the rib section the main spar cannot be placed at the quarter chord of the wing. Each section of the rib can revolve up to 6 degrees upwards or downwards without causing discontinuity on the airfoil cross-section. The wing is actuated through the main spar and sub spar which is interlinked to sub spars. When the main spar is elevated the sub spars rotates relatively so that the chamber is changed.

\section{Conceptual model}

\subsection{CATIA}

The CATIA (Computer Aided Three Dimensional Application) is a multi-platform $\mathrm{CAD} / \mathrm{CAM} / \mathrm{CAE}$ viable software suite developed by the French company Dassault system. The next immediate stage was to design to design software in order to carry out further analysis. CATIA offers a solution to model complex and intelligent products through the system engineering approach. It covers the requirement definition, the system architecture, the behavior modelling and the virtual product or embedded software generation. CATIA can be customized via application programming interfaces (API).CATIA can be adapted using visual basic for application and $\mathrm{C}++$ languages via CAA (Component Application 
Architecture), a component object model (COM)-like interface. The following steps below leads to the 3D design of the wing in modelling software known as CAD Model

\subsection{Airfoil coordinates}

The airfoil coordinates were imported from an airfoil database the lower and upper surface were imported the software. The coordinates of the NACA 0012, NACA 9312 airfoils.

- Baseline rigid configuration airfoil selected for baseline rigid configuration is NACA 0012 with chord length $20 \mathrm{~cm}$ and $36 \mathrm{~cm}$.

- Cambered configuration will obtain from the airfoil selected for baseline rigid configuration is NACA 0012 with chord length $20 \mathrm{~cm}$ and $36 \mathrm{~cm}$.

\subsection{Steps to design}

Step 1. Get the airfoil coordinates for NACA 0012 and NACA 9312 from any airfoil database with a chord of $200 \mathrm{~mm}$ initially. (airfoiltools.com)

Step 2. Open GSV file coordinate in excel

Step3.From CATIA a file named is GSD_PointsplineloftfromExcel.xls copied on to the desktop and the values are replaced with CSV coordinates

Step 4. Join the coordinates of the airfoil.

Step 5. Open CATIA and select the part design and then run the macros in the excel sheet.

Step 6. Similarly, import the CSV coordinates for chord $200 \mathrm{~mm}$

Step 7. Now that we have generated two closed airfoils (NACA 0012-Baseline, NACA 9312-Cambered configuration) section along the $\mathrm{x}$-axis.

Step 8. Now pad the airfoil to the required rib.

Step 9. Save the file and exit.

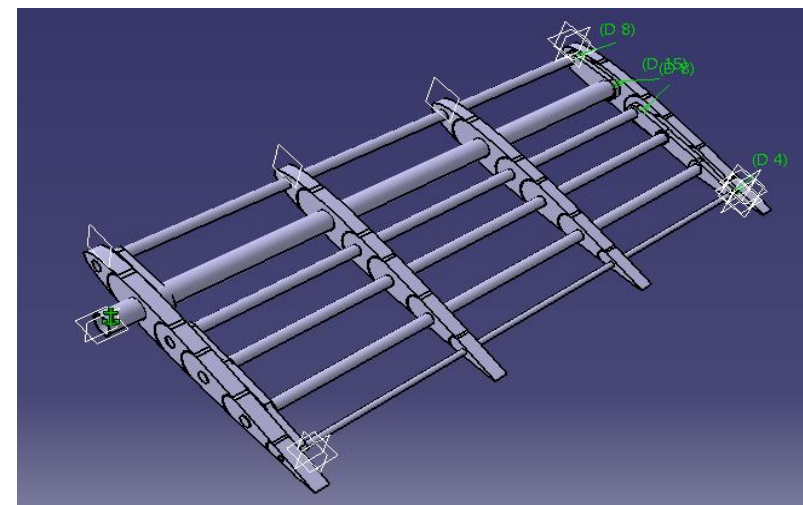

Fig. 2.1: Internal Cross Section of the Morphing Wing in CATIA.

\section{Fabrication process}

The CAD model of morphing wing in the scale of $20 \mathrm{~cm}$ chord and a $36 \mathrm{~cm}$ wingspan. The aluminum materials are selected for the process the block with $5 \mathrm{~mm}$ thinness aluminum $6061 \mathrm{com}$ mercial material is used to process the drilled as for requirement diameters in the 6 rib section to spar connection and also for EDM wire-cut machine. Then aluminum material is processed by the EDM wire-cut machine for the internal ribs with help of the crosssection of the CAD Model. The ribs are made up aluminum material is divided into 6 sections with the help of the EDM wire-cut machine for the higher accuracy and also for smooth flow characterization of the aerodynamic study. The linkage chain mechanism from the leading edge to trailing edge is also processed in the wire cut processed. To achieve the biomimetic the spar and the ribs are covered with the $\mathrm{x}$-rays film and the covering sheet is used for the smooth flow over the morphing wing section.

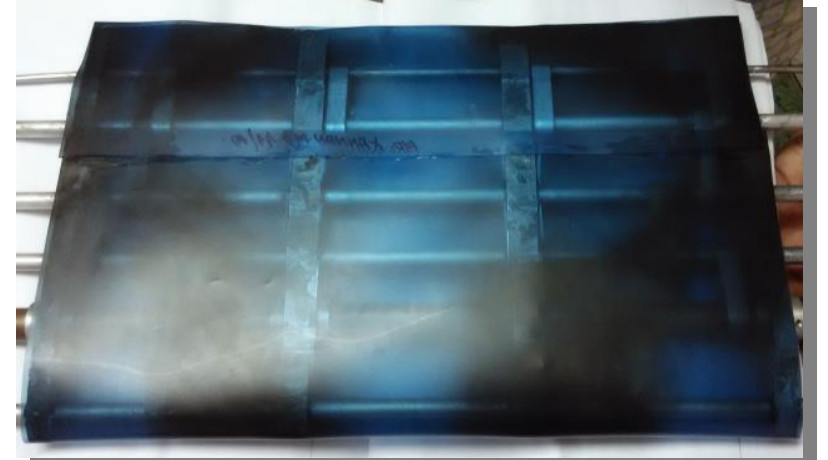

Fig. 3.1: Shows Internal Cross Section of Morphing Wing Covered with X-Rays Sheet.

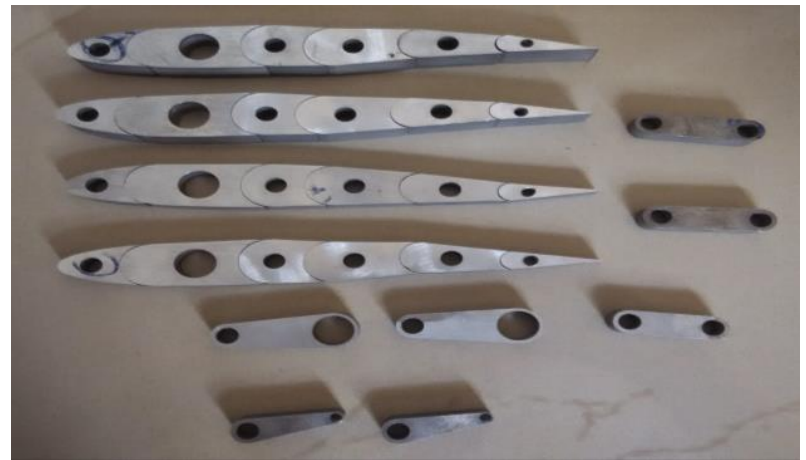

Fig. 3.2: Internal Rib Cross-Section and Linkage Mechanism of Morphing Wing.

\section{Experimental setup}

\subsection{Cascade tunnel}

A flow-through cascade is a row of blades representing the blade ring of the turbomachine. Internal blades are arranged in the straight line or annular, thus representing a real blade row, these preparations are known as 'straight-lined cascade 'and 'annular cascade' respectively. The annular cascade is more concerning a real-life situation. The above arrangements are engaged for the cascades of axial flow turbomachines, but when flow through the ring of blades is in the radial direction, the procedure is termed as a 'radial cascade'. For simulation of actual conditions cascade of blades are tested in the annular form in wind tunnel and as in rotating it is difficult to appreciate flow physic geometry straight cascade or cascade tunnel is used for testing. As a result, it reduces Mechanical complication and interpretation of test result get simplifies in 2D flow conditions.

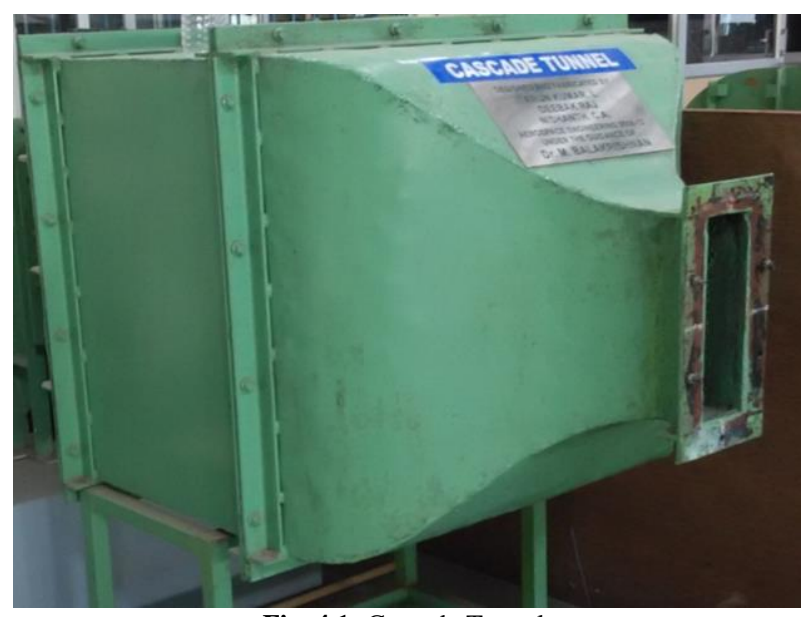

Fig. 4.1: Cascade Tunnel.

The most basic type of instrument used for testing is the physical balance. We must measure two forces Lift and Drag. 
- To completely describe the combination on the model.

- It consists of one physical balance setup to carry the weights on both sides.

- The setup is balanced under static conditions by placing the weight on either side.

- The angle of attack is changed with help of mobile application

- The setup is placed in front of cascade tunnel aligned with the center of the mouth of the tunnel.

- The tubs from the Pitot tube equipment are connected to electronic Manometer which is used to display the velocity.

- The values of Lift and Drag are measured as the weights are placed in the Physical Balanced setup.

\subsection{Experimental process}

- In some wind tunnels, the measuring devices are located outside to the model and the test section. In order tunnels, the measuring devices are placed inside the model. The position of the device affects the choice of mounting system for the model and data reduction required to control the aerodynamic forces. An idealized physical balanced setup is used to measure the lift and drag values.

- Initially, for finding out the lift value, weight is placed in $1: 3$ ratio as shown in the figure. The setup is balanced in the static position with the wing is mounted on the groove section provided in the physical balanced setup. The wind tunnel is switched on and with the help of pitot tubes, the velocity of the flow is measured.

- The physical balanced setup with the wing is placed at a particular distance from the wind tunnel the wing produces some lift value for which is an equal amount of weight is placed on the other side to balance the whole setup.

- The wing is now changed to camber positions with help of a 24 volt DC motor and the lift is calculated by placing the weights on the other side. Similarly, the lift is calculated at different velocities.

- The drag measurement has the setup in 1:1 ratio. Similarly, the drag values are calculated at different velocities by balancing with weight.

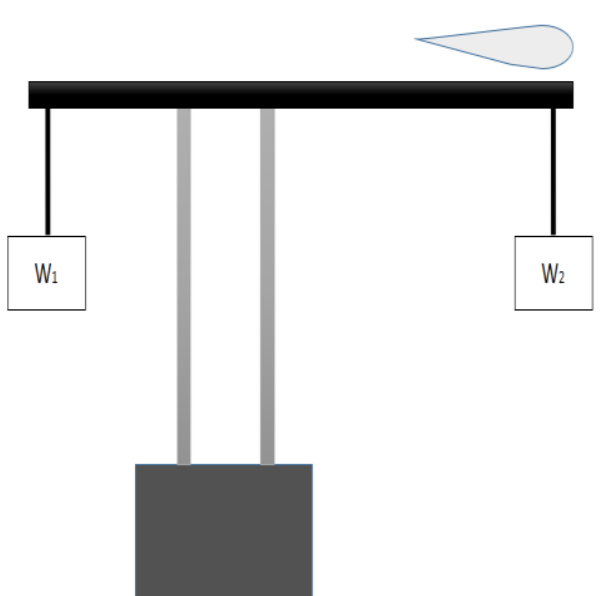

Fig. 4.2: Sketch Showing the Physical Balance Setup.

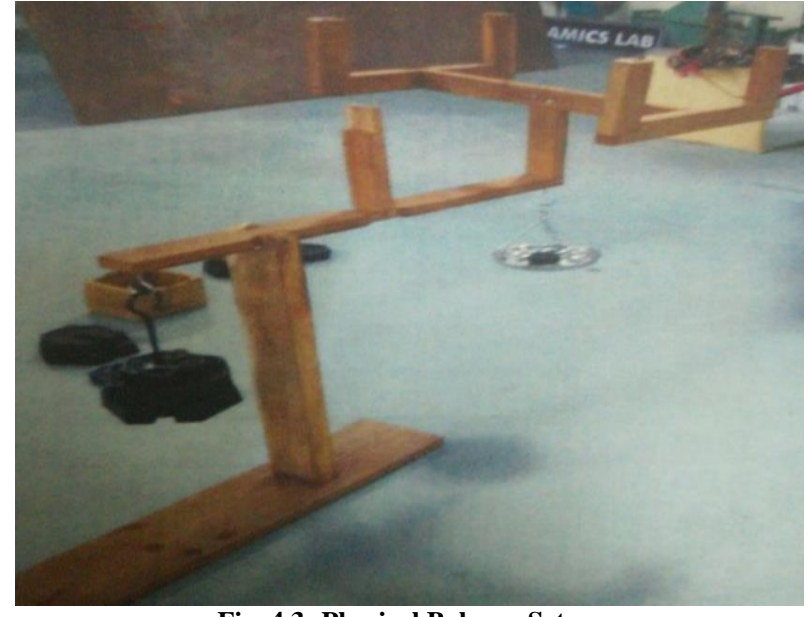

Fig. 4.3: Physical Balance Setup.

\subsection{Test matrix and test procedure}

The morphing wing were tested. Only static tests were performed on these variable cambered wing model. The test matrix is shown in table 4.3.1.

Table 4.3.1: Table Cascade Tunnel Test Matrix

\begin{tabular}{lll}
\multicolumn{3}{c}{ Table 4.3.1: Table Cascade Tunnel Test Matrix } \\
\hline Wing-Model & $\begin{array}{l}\text { Airspeed } \\
\text { (m/s) }\end{array}$ & $\begin{array}{l}\text { Angle of Attack } \\
\text { (degree) }\end{array}$ \\
\hline $\begin{array}{l}\text { MW-Baseline Configuration } \\
\text { MW-Cambered }\end{array}$ & $15,20,25$ & 0 to 12 \\
Configuration & $15,20,25$ & 0 to 12 \\
\hline
\end{tabular}

As displayed above, the wing model test were performed in atmospheric conditions, at three different velocities $15,20,25 \mathrm{~m} / \mathrm{s}$ respectively. Lift and drag were measured from a zero degree angle of attack up to 12 degree. The variable cambers wing was actuated with DC motor to change its camber from baseline configuration to cambered configuration.

The variable baseline configuration, and the variable cambered configuration were tested in cascade tunnel successively. At each angle of attack, each wing was tested at airspeed configuration 15, $20,25 \mathrm{~m} / \mathrm{sin}$ that order. Once all three airspeed were applied, the cascade wind tunnel speed was brought down to the minimum so that the next angle of attack could be set. The change of angle of attack during test was performed manually by loosening the nut holding the main spar to test balance then rotating thee spar to the desired angle of attack. The process was repeated for each wing until the angle of attack reached 12 degrees.

\subsection{Test result}

Table 4.4.1: Test Result for Symmetrical Configuration

\begin{tabular}{llll}
\hline \multicolumn{3}{l}{ Symmetrical configuration } & \\
\hline Velocity & Angle of attack & $\mathrm{Cl}$ & $\mathrm{Cd}$ \\
15 & 0 & 0.0024 & 0.003 \\
15 & 4 & 0.325 & 0.0134 \\
15 & 8 & 0.769 & 0.0245 \\
15 & 12 & 0.953 & 0.04 \\
20 & 0 & 0.036 & 0.003 \\
20 & 4 & 0.425 & 0.0103 \\
20 & 8 & 0.729 & 0.0168 \\
20 & 12 & 1.004 & 0.0359 \\
25 & 0 & 0.0065 & 0.003 \\
25 & 4 & 0.478 & 0.0089 \\
25 & 8 & 0.808 & 0.0173 \\
25 & 12 & 1.23 & 0,0352 \\
\hline
\end{tabular}

Table 4.4.2: Test Result for Cambered Configuration

\begin{tabular}{llll}
\hline \multicolumn{3}{l}{ Cambered configuration } & \\
\hline Velocity & Angle of attack & $\mathrm{Cl}$ & $\mathrm{Cd}$ \\
15 & 0 & 0.0032 & 0.0084 \\
15 & 4 & 1.213 & 0.0194 \\
15 & 8 & 1.689 & 0.0256 \\
15 & 12 & 1.719 & 0.0593 \\
\hline
\end{tabular}




\begin{tabular}{llll}
\hline 20 & 0 & 0.0056 & 0.011 \\
20 & 4 & 1.517 & 0.0153 \\
20 & 8 & 1.893 & 0.0251 \\
20 & 12 & 1.994 & 0.0316 \\
25 & 0 & 0.784 & 0.0145 \\
25 & 4 & 1.256 & 0.0145 \\
25 & 8 & 1.845 & 0.026 \\
25 & 12 & 1.986 & 0.0297 \\
\hline
\end{tabular}

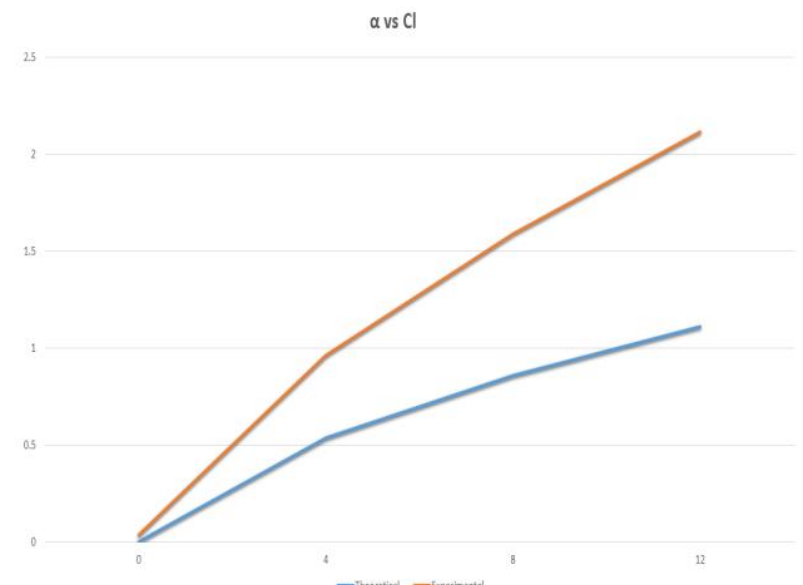

Fig. 5.1.2: Lift Coefficient for Baseline Configuration at $\mathrm{V}=20 \mathrm{~m} / \mathrm{sec}$.

\subsection{Theoretical result}

Table 4.5.1: Theoretical Results for Symmetrical Configuration

\begin{tabular}{llll}
\hline \multicolumn{3}{l}{ symmetrical configuration } & \\
\hline Velocity & Angle of attack & $\mathrm{Cl}$ & $\mathrm{Cd}$ \\
15 & 0 & 0.0 & 0.00 \\
15 & 4 & 0.536166 & 0.0122 \\
15 & 8 & 0.84972 & 0.0205 \\
15 & 12 & 1.083181 & 0.036 \\
20 & 0 & 0.00 & 0.029 \\
20 & 4 & 0.538037 & 0.010 \\
20 & 8 & 0.858183 & 0.0158 \\
20 & 12 & 1.11 & 0.0329 \\
25 & 0 & 0.00 & 0.0029 \\
25 & 4 & 0.528084 & 0.0078 \\
25 & 8 & 0.870186 & 0.0153 \\
25 & 12 & 1.128825 & 0.0312 \\
\hline
\end{tabular}

Table 4.5.2: Theoretical Results for Cambered Configuration

\begin{tabular}{llll}
\hline \multicolumn{5}{l}{ Cambered configuration } \\
\hline Velocity & Angle of attack & $\mathrm{Cl}$ & $\mathrm{Cd}$ \\
15 & 0 & 0.0036 & 0.0094 \\
15 & 4 & 1.316511 & 0.019691 \\
15 & 8 & 1.708801 & 0.028502 \\
15 & 12 & 1.988411 & 0.04665 \\
20 & 0 & 0.893992 & 0.015 \\
20 & 4 & 1.311066 & 0.017087 \\
20 & 8 & 1.704174 & 0.024166 \\
20 & 12 & 1.98399 & 0.03386 \\
25 & 0 & 0.334904 & 0.017087 \\
25 & 4 & 0.493887 & 0.016137 \\
25 & 8 & 1.68904 & 0.022232 \\
25 & 12 & 1.975938 & 0.030453 \\
\hline
\end{tabular}

\section{Observations}

Figures from here display the lift and drag coefficient measured theoretical lift and drag coefficient. Lift comparison between symmetrical and variable cambered configuration are illustrated. One can see that lift coefficient of variable cambered wing are slightly higher than the symmetrical wing. The experimental values of lift are greater than the theoretical values.

\subsection{Lift coefficient for baseline configuration}

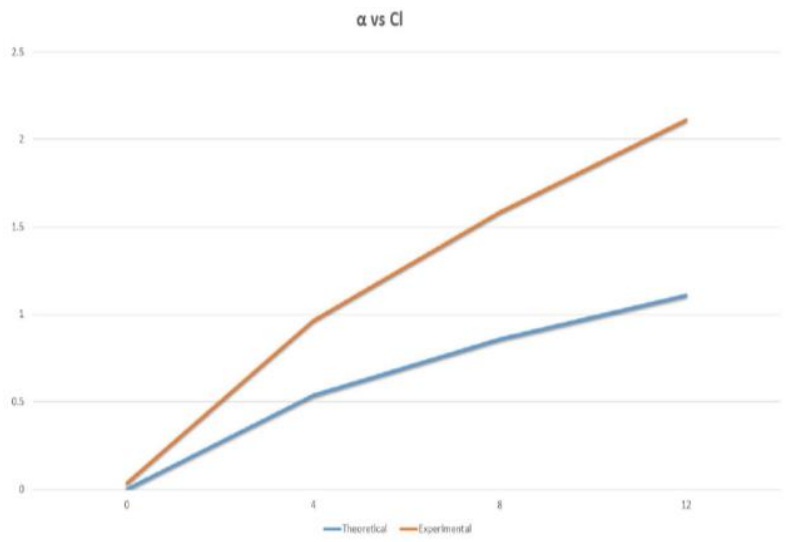

Fig. 5.1.1: Lift Coefficient for Baseline Configuration at $V=15 \mathrm{~m} / \mathrm{sec}$.

\subsection{Lift coefficient for cambered configuration}

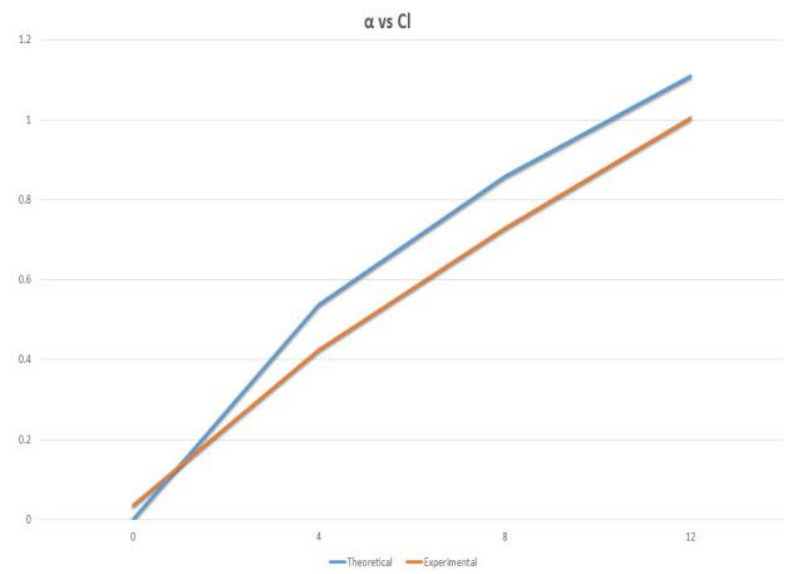

Fig. 5.2.1: Lift Coefficient for Cambered Configuration at $V=15 \mathrm{~m} / \mathrm{sec}$.

Figure 5.2.1 through 5.2.3 display the lift coefficient for the cambered configuration of variable cambered wing. One can see that the drag produced by morphing wing is greater than that of the baseline cambered wing for to the angle of attack. As compared the theoretical lift at high angles of attack velocity but slightly lower lift at low angles of attack. The lift coefficient obtained from morphing wing became smaller than the theoretical values as velocity increases. The baseline configured wing produces lower lift than the theoretical values for all angle of attack. 


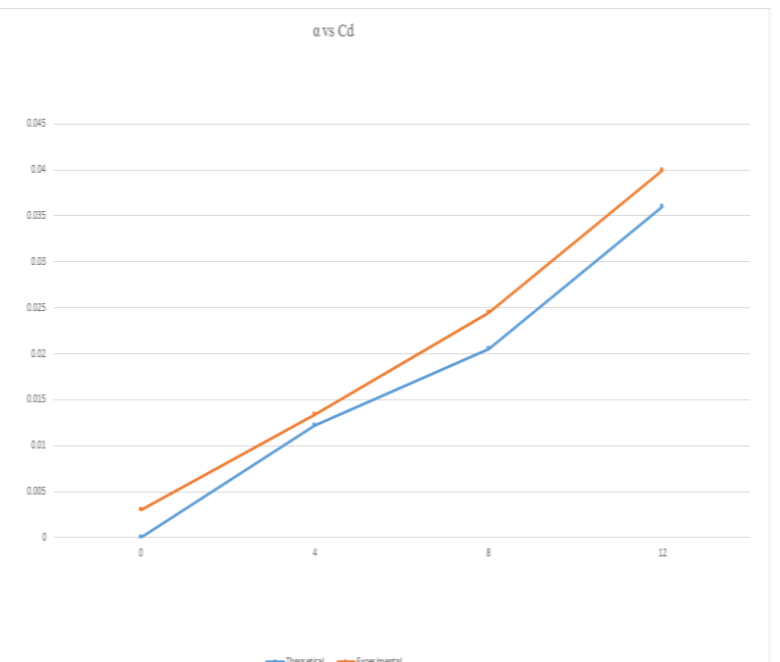

Fig. 5.2.2: Lift Coefficient for Cambered Configuration at $V=20 \mathrm{~m} / \mathrm{sec}$. a vs Cl

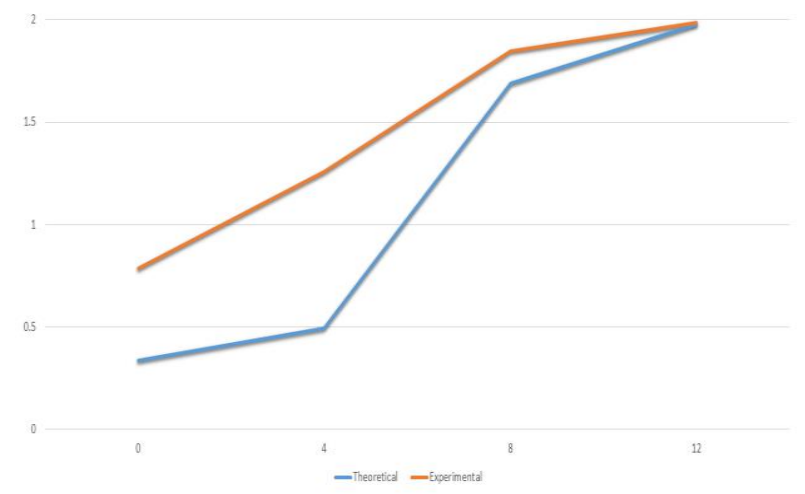

Fig. 5.2.3: Lift Coefficient for Cambered Configuration at $V=25 \mathrm{~m} / \mathrm{sec}$.

\subsection{Drag coefficient for symmetrical configuration}

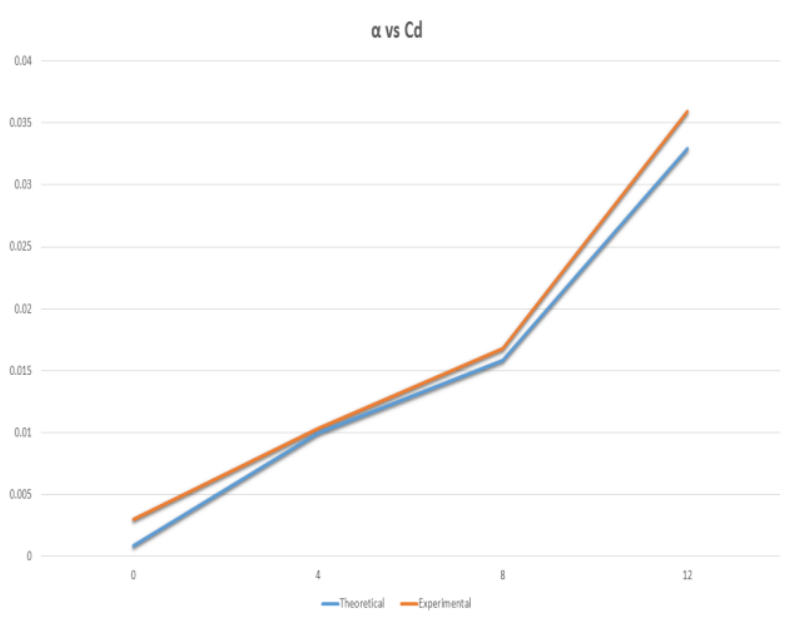

Fig. 5.3.1: Drag Coefficient for Baseline Configuration at $V=15 \mathrm{~m} / \mathrm{sec}$.

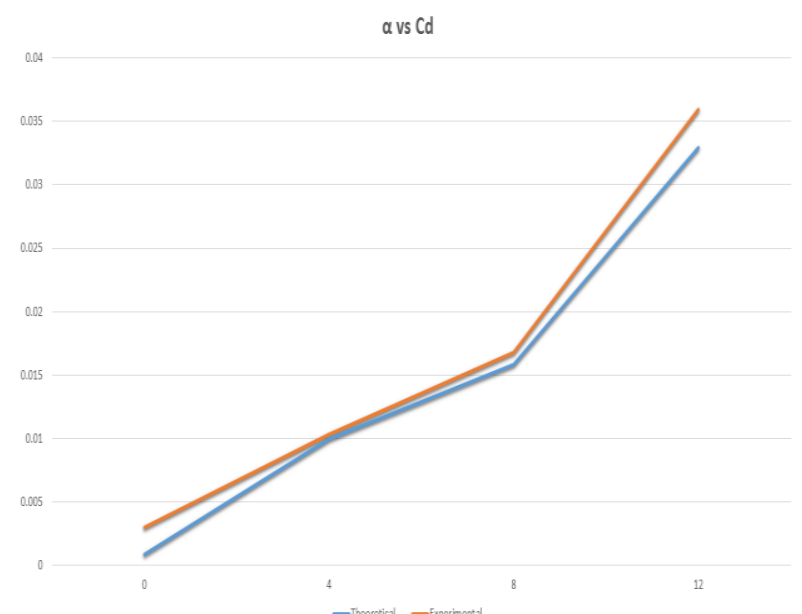

Fig. 5.3.2: Drag Coefficient for Baseline Configuration at $=20 \mathrm{~m} / \mathrm{sec}$.

Figure 5.3.1 through 5.3.3 display the drag coefficient of the variable cambered wing and the theoretical values obtained for Baseline configuration using X-foil software. Drag produced by morphing wing is greater than that of the baseline configured wing and the difference increasers as Velocity increases. The theoretical drag coefficients are lower than the values obtained from the experimental results but close to that of the baseline configured wing.

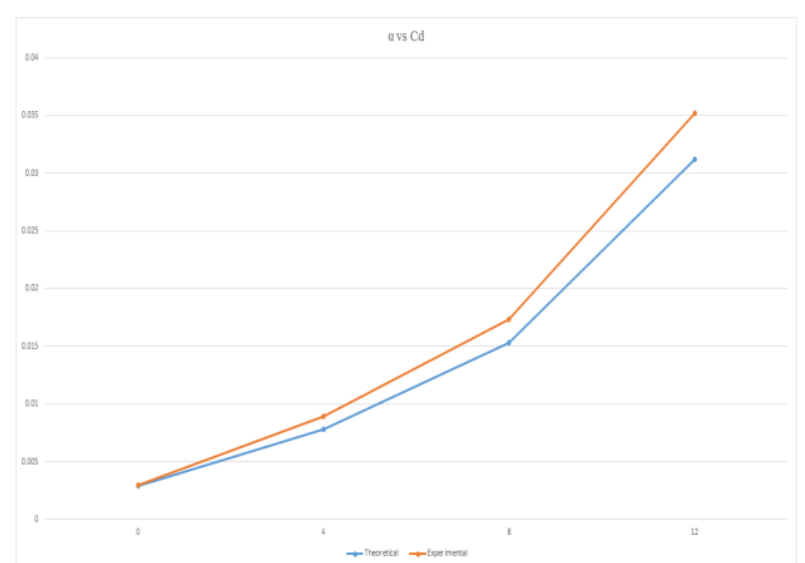

Fig. 5.3.3: Drag Coefficient for Baseline Configuration at $V=25 \mathrm{~m} / \mathrm{sec}$.

Figure 5.4.1 through 5.4.3 display the drag coefficient of the variable cambered wing and the theoretical values obtained for cambered configuration using X-foil program. One can see that the drag produced by morphing wing is less than that of the baseline cambered wing up to the angle of attack. The difference between the cambered wing and baseline wing also increase as the velocity increases just like the baseline case, only opposite. The drag coefficient obtained from X-foil are close to values obtained from morphing wing and slightly higher as velocity 


\subsection{Drag coefficient for cambered configuration}

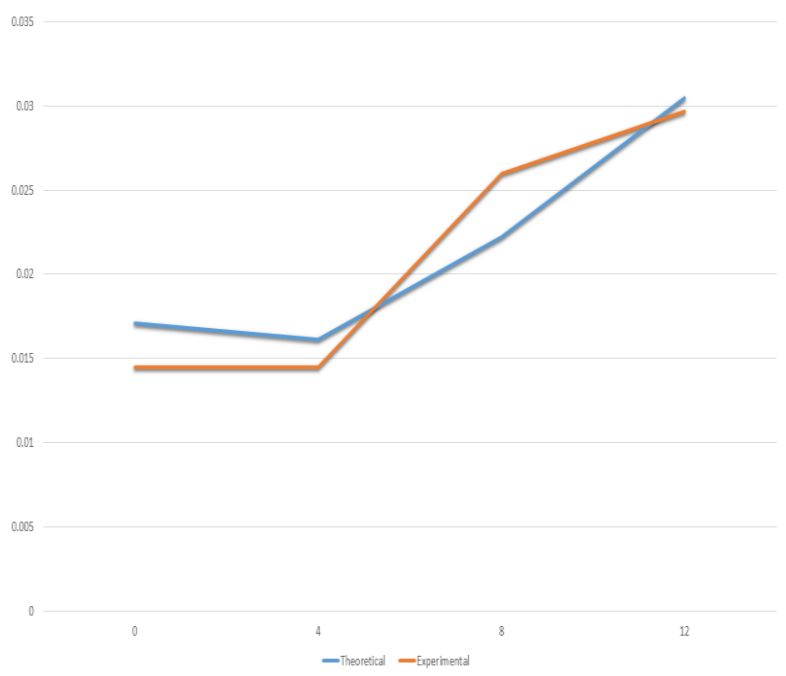

Fig. 5.4.1: Drag Coefficient for Cambered Configuration at $V=15 \mathrm{~m} / \mathrm{sec}$.

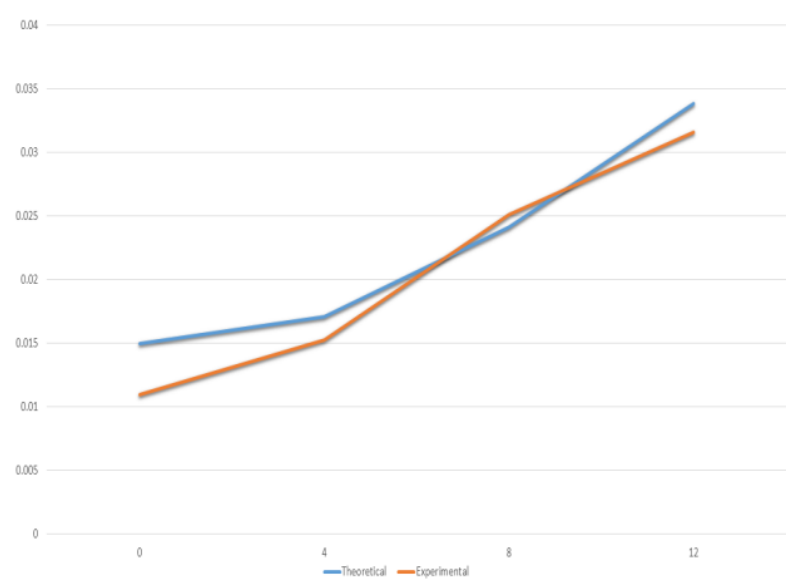

Fig. 5.4.2: Drag Coefficient for Cambered Configuration at $V=20 \mathrm{~m} / \mathrm{sec}$.

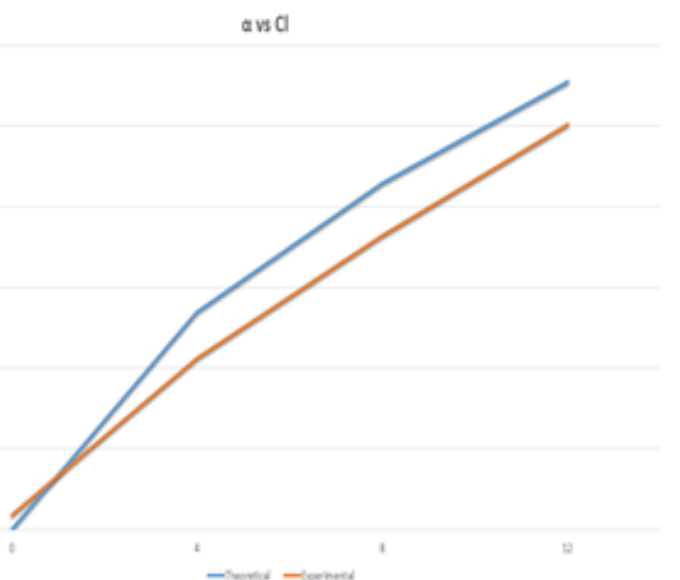

Fig. 5.4.3: Drag Coefficient for Cambered Configuration at $V=25 \mathrm{~m} / \mathrm{sec}$.

\subsection{Summary of test result}

Table 5.5.1: Summary of Test Results at $V=15 \mathrm{~m} / \mathrm{sec}$

\begin{tabular}{lll}
\hline Parameters & $\begin{array}{l}\text { MW-Baseline } \\
\text { configuration }\end{array}$ & $\begin{array}{l}\text { MW-Cambered } \\
\text { configuration }\end{array}$ \\
\hline Max Cl & at 12 deg is 1.23 & at 12 deg is 1.986 \\
Max Cd & at 12 deg is 0.0352 & at 12 deg is 0.0297 \\
\hline
\end{tabular}

Table 5.5.2: Summary of Test Results at $V=25 \mathrm{~m} / \mathrm{sec}$

Parameters

MW-Baseline

MW-Cambered configuration

\begin{tabular}{|c|c|c|}
\hline $\begin{array}{l}\mathrm{Max} C l \\
\operatorname{Max} \mathrm{Cd}\end{array}$ & $\begin{array}{l}\text { at } 12 \mathrm{deg} \text { is } 1.004 \\
\text { at } 12 \mathrm{deg} \text { is } 0.0359\end{array}$ & $\begin{array}{l}\text { at } 12 \mathrm{deg} \text { is } 1.994 \\
\text { at } 12 \mathrm{deg} \text { is } 0.0316\end{array}$ \\
\hline \multicolumn{3}{|c|}{ Table 5.5.3: Summary of Test Results at $\mathrm{V}=25 \mathrm{~m} / \mathrm{sec}$. } \\
\hline Parameters & $\begin{array}{l}\text { MW-Baseline } \\
\text { configuration }\end{array}$ & $\begin{array}{l}\text { MW-Cambered } \\
\text { configuration }\end{array}$ \\
\hline & at 12 deg is 0.95 & at $12 \mathrm{deg}$ is 1.719 \\
\hline
\end{tabular}

\section{Conclusion}

A morphing wing, using six rib section with dc motors and simple linkage system embedded inside the wing was designed as means to vary the shape of a wing based on the biomimetic.

This morphing wing did not involve complicated actuation components or a control system, but effectively provided satisfactory changes in wing chamber. A change in camber around $10 \%$ before applying the wing skin, were obtained from this wing concept The size of wing model was determined from the test result of other wing models previously in the same wind tunnel. The aluminum rib section Manufactured by wire cutting EDM machine, the chain links were the primary structures of the morphing wind tunnel model. The morphing wing was covered by the combination of X-rays sheet and nylon materials which is provided very satisfactory flexibility, strength and stiffness. The X-rays sheet showed low magnitude but high-frequency vibration during testing causing the flow to attach to the wing and delay separation. This was expected phenomenon which benefited the test results. This research was done in cascade wind tunnel. A physical test balance was used to measure lift and drag. The measured aerodynamics coefficients were used to determine the advantages of morphing wing over that of the rigid wing

The wind tunnel was also used to compare with calculated values obtained from the X-foil software. The static test was performed at an airspeed of $15 \mathrm{~m} / \mathrm{s}, 20 \mathrm{~m} / \mathrm{s}, 2 \mathrm{~m} / \mathrm{s}$ respectively, in the same atmosphere conditions for all three wings. The wind tunnel results showed significant advantages of the morphing wing over symmetric wings such as lift values and higher lift to drag ratio. However, due to high drag generated by the wing skin of the morphing wing during baseline configuration, the lift to drag ratio of morphing wing was lower than the baseline rigid wing.

\section{Acknowledgements}

We are grateful and thankful to our project guide, Mr.S.Rajkumar, Asst. Professor (OG), SRM Institute of Science and Technology, kattankulathur, for his guidance and kind Co- operation to complete this project.

\section{References}

[1] Martins, J. R. (2016). Fuel Burn Reduction through Wing Morphing. Encyclopedia of Aerospace Engineering.

[2] Tunçöz, İ. O. (2015). Design and analysis of a hybrid trailing edge control surface of a fully morphing unmanned aerial vehicle wing. Yüksek Lisans Tezi, Havacılık ve Uzay Mühendisliği Bölümü, Orta Doğu Teknik Üniversitesi, Ankara

[3] Nadar, A., Khan, R., Jagnade, P., Limje, P., Bhusari, N., \& Singh, K. (2013). Design and Analysis of Multi-Section Variable Camber Wing. International Journal on Mechanical Engineering and Robotics, 1(1), 122-128. 